Assiut Scientific Nursing Journal

http://asnj.journals.ekb.eg

http://www.arabimpactfactor.com

\title{
Effect of non-pharmacological Methods on Pain Reduction in First Stage of Labor at Sohag University Hospital
}

\author{
Zeinab A. Ali ${ }^{1}$, Mervat A. khamis ${ }^{2}$, Nour Al Houda M. Mohammed ${ }^{3} \&$ Mohammed Nour El-Dien Salem $^{4}$. \\ - Assistant lecturer of Obstetrics and Gynecologic Nursing, Faculty of Nursing- Sohag University, Egypt. \\ 2. Professor of Obstetrics and Gynecology Nursing, Faculty of Nursing, Assiut University, Egypt. \\ Assistant Professor of Obstetrics and Gynecologic nursing, Faculty of Nursing, Sohag University, Egypt. \\ 4. Lecturer of Obstetrics and Gynecologic Medicine, Faculty of Medicine- Sohag, University, Egypt.
}

\begin{abstract}
Background: Labor is a health state that most women aspire to at some point in their lives. The first thought that comes to the woman's mind regarding delivery is the pain of labor. The aim of the study to evaluate effect of nonpharmacological methods on pain reduction in first stage of labor at Sohag University Hospital. Subjects and Methods: Design Quasi-experimental design was used to conduct this research Setting: this study was carried out at obstetric emergency department at Sohag University Hospital. Sample: the sample consisted of a purposive sample 150 women. Tools used in this study, Tool I: Patient assessment sheet. Tool II: Visual Analogue Scale. Tool III: Participants satisfaction tool. The main results: It revealed that there was statistical significance difference on pain reduction before applying back massage and reflexology and after applying them with p-value $=0.000$. Conclusion According to our study valid evidence for effect of back massage and reflexology on pain reduction in first stage of labor. Recommendation: The System of nursing care should include non-pharmacological pain relieve measures as back massage and reflexology when providing maternity care during labor.
\end{abstract}

\section{Keywords: Back massage, First stage, Labor, Non- Pharmacological Methods, Pain Reduction \& Reflexology.}

\section{Introduction}

Labor is a health condition that most women aspire to at some point in their lives. The first thought that comes to the mind of an expecting woman regarding her delivery is the pain of labor. The pain of the labor is the central and universal part of woman's experience of childbirth. Labor is a normal physiological process, which while should be an occasion for rejoicing, it also accompanies with it lots of pain, agony, and discomfort and certain risks. Thus although being a joyful and empowering experience it can end with negative and tragic consequences, leaving the woman filled with fear and anxiety for future birth. (NCI, 2014)

Labor is divided into four stages; First stage begins from the onset of true labor pain and ends with full dilatation of cervix. It is in other words, the cervical stage of labor. Second stage of labor begins with full dilatation of cervix and ends with the expulsion of fetus. Third stage starts after the expulsion of fetus and ends with the expulsion of placenta and membranes. Fourth stage is the stage of observation of at least one hour after the expulsion of placenta and membranes.( Adel \& Ahmed, 2017)

The pain and discomfort of labor have two origins visceral and somatic. During the first stage of labor, uterine contractions cause cervical dilation and effacement. Uterine ischemia (decreased blood flow and therefore local oxygen deficit) results from compression of the arteries supplying the myometrium during uterine contractions. Pain impulses during the first stage of labor are transmitted via the T10 to T12 and L1 spinal nerve segments and accessory lower thoracic and upper lumbar sympathetic nerves. (Gousia, 2015).

Labor pain management can be done in two ways; pharmacological and non-pharmacological ways.(Davim, et al., 2010). Pharmacological measures are often expensive and have harmful effects for reducing labor pain. In the such methods, the pain feeling would be reduced physiologically but psychological and emotional conditions of the mothers are ignored, the pharmacological methods of pain relieving including receiving narcotics drugs such as Pethidine . (Funai \& Norwitz, 2012)

The non-pharmacological methods including wide variety of techniques that address not only the physical sensations of pain, but also attempt to prevent suffering by enhancing the psycho-emotional and spiritual components of care such as massage, muscle relaxation, breathing techniques, music therapy, mind body techniques, reflexology, herbal medicines, hypnosis, and touch therapy are some types of complementary and alternative medicine that use to reduce the pain in the world. Nonpharmacological methods for pain relief during labor stage can reduce need for analgesic drug taking. (Matourypour, et al., 2016) 
Massage is the systematic movement of the soft tissues of the body particularly the muscles, tendons and skin. It also relaxes tense muscles by promoting general relaxation. Moreover, it motivates endorphin release, increases serotonin and inhibits the transmission of noxious nerve signals to the brain (Smith, 2018)

Reflexology session involves the application of pressure using specific thumb and finger technique, stretching and movement on reflex points located in the feet, hands and ears. The most common site for treatment is the foot. (Smith, et al., 2018)

The major role and responsibilities of the nurse is to identifying the problems of the woman in labor, providing appropriate information regarding the alternative modalities of pain relief during labor, helps the women to ventilate all their doubts by interpersonal interactions, helps the women in labor to select the appropriate modality for effective pain relief, effective application of alternative modalities of pain relief during first stage of labor and there by managing labor pain effectively. (Deepika \& Seema, 2017)

\section{Significance of the study}

It has been observed that nurses pay a little attention to control labor pain and they go about their routine nursing care as hourly vital signs assessment and hourly fetal heart rate monitoring without attention to labor pain. They see labor pain as natural phenomena occur to each woman. (AbdEI Fadeel, 2015)

Labor pain is the most severe pains in the world. (Kamali, et al., 2010) Severe labor pain causes distress for mother and can impair her health. It might also have negative effects on child-mother and marital relationships.( Wall et al., 2000). According to previous studies, the fear of tolerating vaginal delivery pain has significantly increased the number of cesarean sections in $\operatorname{Iran}($ Bahri et al., 2008) although there are a number of nonpharmacological interventions to relieve pain.( Potter \& Perry, 2009) Studies performed in 2001 on 4171 American women revealed that $84 \%$ of women tended to use non-pharmacological methods to decrease labor pain and the commonest methods were breathing techniques (55.2\%) and massaging (17.3\%).( Sullivan, 2005)

Implementation of different techniques is timeconsuming and costly. On the other hand, a safe method to control pain should certainly be effective, affordable and accessible as well as less hazardous for both the mother and the fetus. Comparing the commonest methods seems necessary in order to determine the most effective method. Thus, we tried to compare the effects of massage therapy and reflexology techniques on pain reduction during first stage of labor.

Aim of the study

The aim of this study was to evaluate effect of nonpharmacological on pain reduction in first stage of labor at Sohag University Hospital.

\section{Hypothesis}

To fulfill the aim of this study the following research hypothesis is formulated

- Women in first stage of labor will demonstrate pain reduction with the use of back massage or not.

- Women in first stage of labor will demonstrate pain reduction with the use of reflexology or not.

\section{Subjects \& Method}

Design: Quasi-experimental designs was conducted in the study.

Setting: This study was conducted at labor and delivery department at Sohag University Hospital.

Sample: The sample was consist of a purposive sample 150 women attending labor and delivery department at Sohag University Hospital with a precision of $5 \%, \alpha=0,05$ and power of $95 \%$.

Inclusion criteria: All primigravida women admitted in labor room and in first stage of labor with vertex presentation and full term pregnancy and willing to participate in the study.

Exclusion criteria: Women with any complication such as pregnancy-induced hypertension, gestational diabetes mellitus etc, women getting epidural or any pain relieving medication, presence of dermatologic conditions that would contraindicate the application of massage and during the study incidence of any non-diagnosed dystocia.

Tools of data collection: Data were collected using three tools. It was developed by the investigator based on literature review and all tools were filled by the researcher.

\section{Tool I: Participants assessment sheet}

This tool was developed by the investigator used to assess the studied Participants regard the sociodemographic data, menstrual history and obstetric history. It divided into three parts Socio demographic data includes patient's age, level of education, occupation and resident, menstrual history and obstetric history.

Tool II: Visual Analogue Scale: This scale is adopted from Gift (1989) and consists of a blank line $(10 \mathrm{~cm})$ that describes the extremes of pain. Commonly used are "no pain" and "severe pain" (worst possible pain). The woman is asked to place a mark on the line that best indicate the pain being experienced. Scoring system: measuring from the end of the line to the mark made by the woman gives 
a numeric rating of the intensity of the pain. The score zero (0) indicate no pain and the top score (10) indicates the worst possible pain. Score level (0-3 Mild pain; 4-6 Moderate pain; 7-10 Sever pain) and categorized by the investigator into 3 colored categories (green, orange\& red). Green color and its degrees $(0-3 \mathrm{~cm})$ for mild pain, orange color and its degrees $(4-6 \mathrm{~cm})$ for moderate pain and red color $(7-$ $10 \mathrm{~cm}$ ) for severe pain. The women were asked to point on the three types of colored categories the perceived level of pain she felt among the both groups.

Tool III: participant satisfaction tool.: This tool is used to get the behavioral responses of study group regarding intervention applied by the researcher to reduce pain in first stage of labor and response of control group regarding routine care by the team work and applied for women every 30 minutes throughout the active acceleration phase of labor from $4-7 \mathrm{~cm}$ and active deceleration phase from $8-10 \mathrm{~cm}$ of full cervical dilatation and it includes 6 items.( 1-The investigator that treated you was friendly and professional ,2-the purpose of intervention and tailored it to fit your needs , 3-the investigator gave you opportunity to ask any questions regarding intervention, 4-the investigator checked in with you to make sure that you was comfortable with the amount of pressure being applied, 5- the intervention room was neat and clean, 6- there is improvement in your muscles tension and pain level after intervention.)

Scoring if women answered 6 items $=$ satisfaction, $3-5$ items $=$ moderate satisfaction, $0-2$ items $=$ un satisfaction.

The Validity was tasted for content by jury of five experts in the field of Obstetrics' and Gynecological Nursing Specialty to ascertain relevance and

completeness; reviewed the questionnaire and the intervention for content and face validity $(r=0.89)$. Their comments were reviewed and the necessary modifications were done.

\section{Methods}

\section{Ethical considerations}

An official permissions was obtained to carry out the study from Dean of Faculty of Nursing, Director of University Hospital- Sohag University.

Research proposal was approved from Ethical Committee in the Faculty of Nursing-Assiut University. Oral consent was obtained from women that are willing to participate in the study and had the right to refuse without any rational. Confidentiality and anonymity was assured.

\section{A pilot study}

carried out before starting of data collection to test the feasibility and clarity of the study tools. It was done on $10 \%$ of the sample, the analysis of pilot study done to define the modification required in the tool used, and The participants(women) in the pilot study were excluded from the actual study.

\section{Intervention}

- Assessment sheet is used before delivery to collect data related to socio-demographic characteristics and obstetric profile. The researcher met the women at the labor and delivery department where they came for delivery. She asked questions in simple Arabic language and recorded the answers in the sheet. The researcher consumed about 20 minutes for each woman. As well as the level of pain assessment using visual analogue scale before implementation of the intervention. In labor room of the maternity ward, participants of the study were separated (if possible) in empty room in department if it is available and in entire duration of the study, emotional, verbal and nonverbal relationship and spiritual support were established between the pregnant mother and the researcher.

- Data collection are done by the researcher from March to December 2018 and he sample was divided into two groups randomly Group (A) control group consists of 50 women who received routine hospital care where researcher went to labor department three days per week in the first 3 months ( from March to June) to collect them and then group (B) study group consists of 100 women which divided into two groups : group (1) consists of 50 women who received back massage were collected in the second 3 months ( from July to September) and group (2) consists of 50 women who received reflexology were collected in the last 3 months (from October to December)

- The implementation phase of massage and reflexology was carried out at the end of assessment phase and was followed up till the end of active phase of labor (active acceleration and active deceleration). After obtaining verbal consent, the investigator explained to participant how to mark her pain intensity at the present moment using the Visual Analogue Scale.

- The experimental group received massage from researcher at the beginning of the active phase of labor during the period of $3-5 \mathrm{~cm}$ of cervical dilation and during uterine contractions for 30 minutes. The intensity of the massage was determined by the participant, who was instructed to request greater or lesser force during execution of the massage according to her preference. The technique was applied between T10 and S4, which corresponds to the path of the hypogastric plexus and the pudendal nerve, responsible for innervation of the 
paravertebral ganglia, delivery canal, and perineum. The massage consisted of rhythmic, ascending, kneading hand movements and a return with sliding through the lateral region of the trunk in association with sacral pressure. The participants were also instructed to choose their preferred position for receiving massage, ie, sitting, lateral decubitus, or standing with the trunk bending forward.

- For the reflexology session, thumb and index fingers were used to work on the feet. First mild massage was given on all feet and then pressure was applied on concerned and specified regions. As Figure1 shows, these areas were: 1) Pituitary gland, in the center of the thumb; 2) Solar plexus, almost four fingers width below the base of the fingers of the feet, located in the center (middle of diaphragm); 3) Lumbar and sacral spine (spinal cord region) and 4) Genital area, below the ankle.

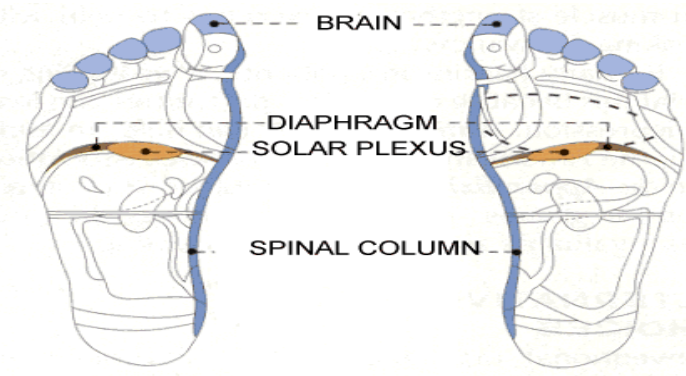

\section{Evaluation phase}

In this phase, information about the effectiveness of massage and reflexology on labor pain was assessed by using Visual Analogue Scale to be easily understood by the laboring woman and to achieving accurate scoring, the scale was categorized by the investigator into 3 colored categories (green, orange\& red). Green color and its degrees $(0-3 \mathrm{~cm})$ for mild pain, orange color and its degrees $(4-6 \mathrm{~cm})$ for moderate pain and red color $(7-10 \mathrm{~cm})$ for severe pain. The women were asked to point on the three types of colored categories the perceived level of pain she felt among the both groups also mother's satisfaction regarding the effect of massage and reflexology on relieving labor pain were also assessed.

\section{Statistical analysis}

Analyses were conducting by using SPSS 20.0 software. The categorical variables were described by number and percent $(\mathrm{N}, \%)$ where continuous variables described by mean and standard deviation (Mean, SD).Chi-square test used to compare between categorical variables where compare between continuous variables t-test.

\section{Results}

The current study was aimed to evaluate effect of back massage and reflexology on pain reduction in first stage of labor at Sohag University Hospital.

Table (1): socio-demographic status of women

\begin{tabular}{|c|c|c|c|c|c|c|c|}
\hline \multirow{3}{*}{\multicolumn{2}{|c|}{ Variables }} & \multicolumn{4}{|c|}{$\begin{array}{c}\text { Study group } \\
\mathbf{N}=100\end{array}$} & \multirow{2}{*}{\multicolumn{2}{|c|}{$\begin{array}{c}\begin{array}{c}\text { Control group } \\
\mathrm{N}=\mathbf{5 0}\end{array} \\
\text { Routine care }\end{array}$}} \\
\hline & & \multicolumn{2}{|c|}{ Back massage } & \multicolumn{2}{|c|}{ Reflexology } & & \\
\hline & & $\mathrm{N}=\mathbf{5 0}$ & $\%$ & $\mathrm{~N}=\mathbf{5 0}$ & $\%$ & $\mathrm{~N}=\mathbf{5 0}$ & $\%$ \\
\hline \multirow{3}{*}{ Age(years) } & Less than 25 & 7 & 14.0 & 17 & 34.0 & 13 & 26.0 \\
\hline & $25-30$ & 25 & 50.0 & 26 & 52.0 & 27 & 54.0 \\
\hline & More than 30 & 18 & 36.0 & 7 & 14.0 & 10 & 20.0 \\
\hline \multirow[b]{2}{*}{ Occupation } & Housewife & 34 & 68.0 & 40 & 80.0 & 46 & 92.0 \\
\hline & Employee & 16 & 32.0 & 10 & 20.0 & 4 & 8.0 \\
\hline
\end{tabular}




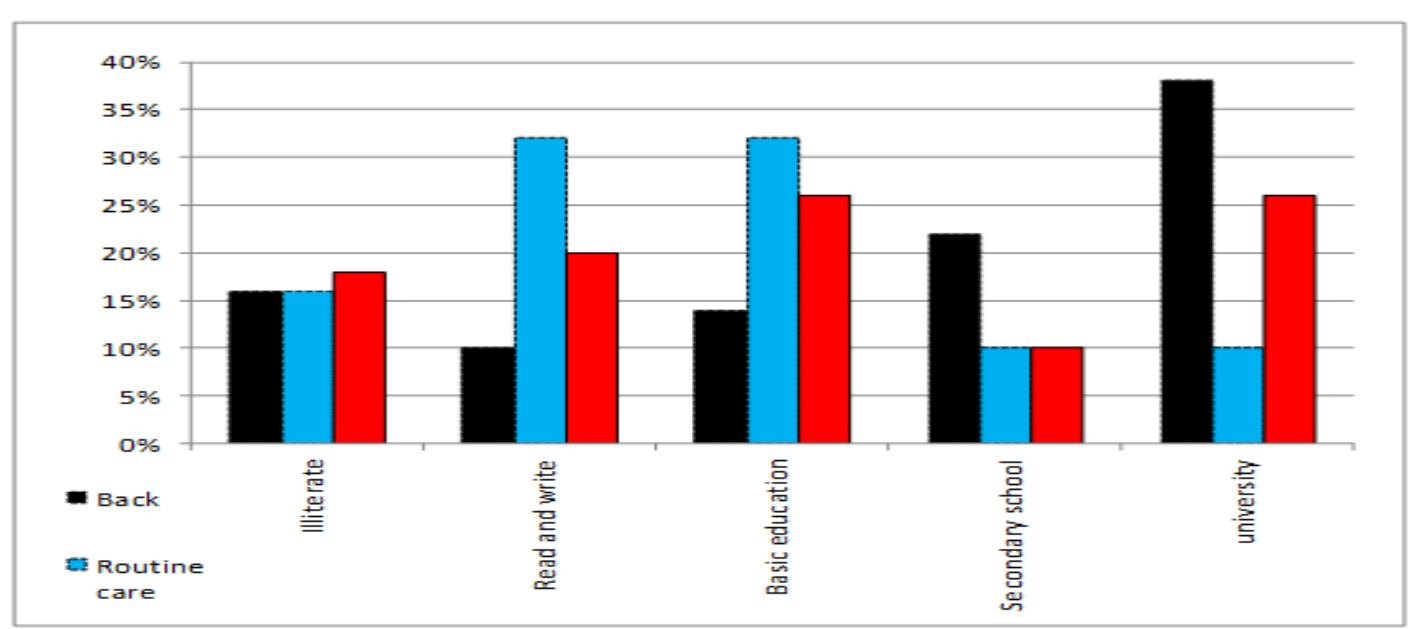

Figure (1): socio- demographic (Level of education).

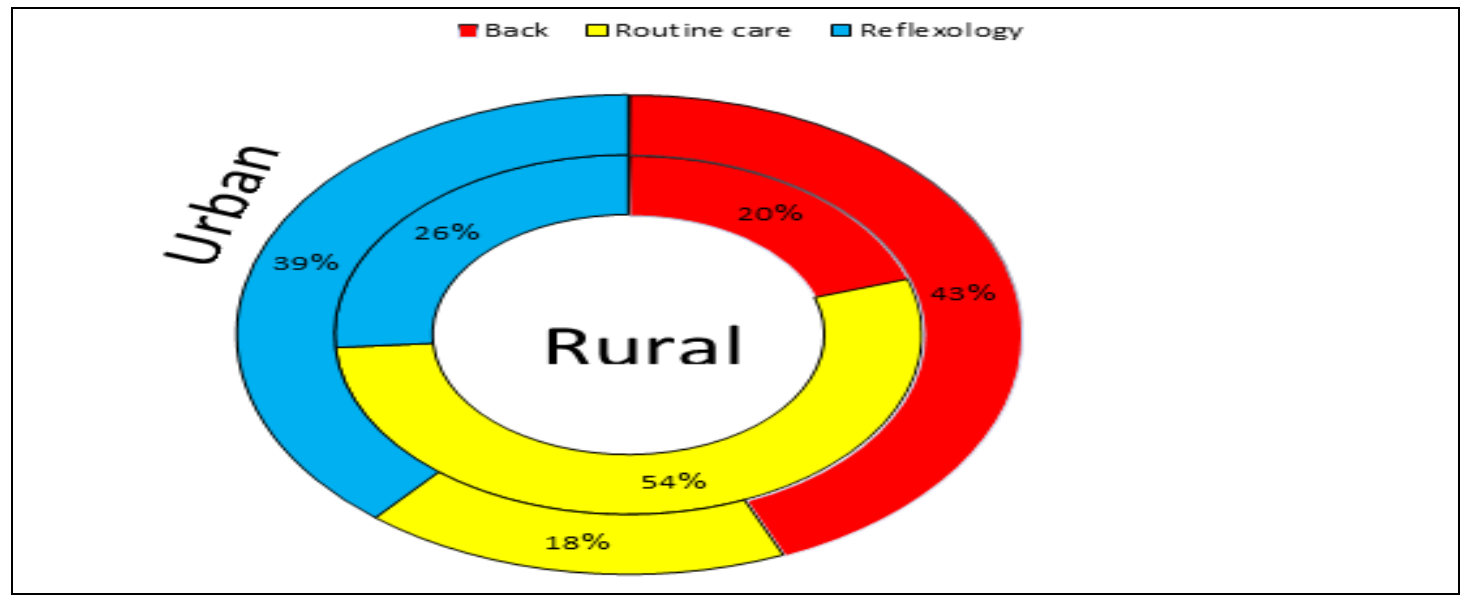

Figure (2) : socio- demographic (Residence).

Table (2): Comparison of labor pain scores at the first stage of labor before and after back massage.

\begin{tabular}{|c|c|c|c|}
\hline \multirow{2}{*}{ Cervical Dilatation } & Before & After & \multirow{2}{*}{ P value } \\
\cline { 2 - 3 } & Mean \pm S.D & Mean \pm S.D & \\
& .6000 & .0400 & .000 \\
\hline $3-5$ centimeters & \pm .57143 & \pm .19795 & .000 \\
\hline & 1.3200 & .4600 & \\
6-8 centimeters & \pm .51270 & \pm .50346 & .000 \\
\hline
\end{tabular}

Level of significance at $p<0.05$

Table (3): Comparison of labor pain scores at the first stage of labor before and after reflexology

\begin{tabular}{|c|c|c|c|}
\hline \multirow{2}{*}{ Cervical Dilatation } & Before & After & \multirow{2}{*}{ P value } \\
\cline { 2 - 3 } & Mean \pm S.D & Mean \pm S.D & .000 \\
\hline 3-5 centimeters & $.3000 \pm .46291$ & $.0000 \pm .00000$ & .000 \\
\hline 6-8 centimeters & $1.1400 \pm .35051$ & $.1600 \pm .37033$ & .000 \\
\hline 9-10 centimeters & $1.9600 \pm .19795$ & $.9600 \pm .19795$ & \\
\hline
\end{tabular}

Level of significance at $p<0.05$ 
Table (4): Comparison of satisfaction items between routine care of the hospital and back massage at the first stage of labor.

\begin{tabular}{|c|c|c|c|c|}
\hline Satisfaction items & & \multicolumn{2}{|c|}{ Mean \pm STD } & P.Value \\
\hline \multirow{2}{*}{$\begin{array}{l}\text { The investigator that treated you was } \\
\text { friendly and professional }\end{array}$} & Routine care & 3.0600 & $.79308 \pm$ & \multirow{2}{*}{.000} \\
\hline & Back massage & 4.1800 & $.71969 \pm$ & \\
\hline \multirow{2}{*}{$\begin{array}{l}\text { The investigator told you about } \\
\text { purpose of intervention and tailored it } \\
\text { to fit your needs. }\end{array}$} & Routine care & 2.6400 & $.56279 \pm$ & \multirow{2}{*}{.000} \\
\hline & Back massage & 4.3000 & $.67763 \pm$ & \\
\hline \multirow{2}{*}{$\begin{array}{l}\text { The investigator gave you opportunity } \\
\text { to ask any questions regarding } \\
\text { intervention }\end{array}$} & Routine care & 2.5200 & $.54361 \pm$ & \multirow[b]{2}{*}{.000} \\
\hline & Back massage & 4.2800 & $.67128 \pm$ & \\
\hline \multirow{2}{*}{$\begin{array}{l}\text { The investigator checked in with you } \\
\text { to make sure that you was comfortable } \\
\text { with the amount of pressure being } \\
\text { applied }\end{array}$} & Routine care & 2.4600 & $.50346 \pm$ & \multirow[b]{2}{*}{.000} \\
\hline & Back massage & 4.0400 & $.66884 \pm$ & \\
\hline \multirow{2}{*}{$\begin{array}{l}\text { The intervention room was neat and } \\
\text { clean. }\end{array}$} & Routine care & 2.6800 & $.51270 \pm$ & \multirow{2}{*}{.000} \\
\hline & Back massage & 3.8000 & $.72843 \pm$ & \\
\hline \multirow{2}{*}{$\begin{array}{l}\text { There is improvement in your } \\
\text { muscles tension and pain level after } \\
\text { intervention }\end{array}$} & Routine care & 2.4400 & $.50143 \pm$ & \multirow[b]{2}{*}{.000} \\
\hline & Back massage & 4.3200 & $.62073 \pm$ & \\
\hline
\end{tabular}

Level of significance at $p<0.05$

Table (5): Comparison of satisfaction items between back massage and reflexology at the first stage of labor.

\begin{tabular}{|c|c|c|c|c|}
\hline Satisfaction items & & \multicolumn{2}{|c|}{ Mean \pm STD } & P. Value \\
\hline \multirow{2}{*}{$\begin{array}{l}\text { The investigator that treated you was } \\
\text { friendly and professional }\end{array}$} & Back massage & 4.1800 & \pm .71969 & \multirow[t]{2}{*}{.001} \\
\hline & Reflexology & 4.6400 & \pm .56279 & \\
\hline \multirow{2}{*}{$\begin{array}{l}\text { The investigator told you about } \\
\text { purpose of intervention and tailored it } \\
\text { to fit your needs. }\end{array}$} & Back massage & 4.3000 & \pm .67763 & \multirow[t]{2}{*}{.004} \\
\hline & Reflexology & 4.6600 & \pm .51942 & \\
\hline \multirow{2}{*}{$\begin{array}{l}\text { The investigator gave you opportunity } \\
\text { to ask any questions regarding } \\
\text { intervention }\end{array}$} & Back massage & 4.2800 & \pm .67128 & \multirow[t]{2}{*}{.059} \\
\hline & Reflexology & 4.5200 & \pm .57994 & \\
\hline \multirow{2}{*}{$\begin{array}{l}\text { The investigator checked in with you } \\
\text { to make sure that you was } \\
\text { comfortable with the amount of } \\
\text { pressure being applied }\end{array}$} & Back massage & 4.0400 & \pm .66884 & \multirow[t]{2}{*}{.023} \\
\hline & Reflexology & 4.3400 & \pm .62629 & \\
\hline \multirow{2}{*}{$\begin{array}{l}\text { The intervention room was neat and } \\
\text { clean. }\end{array}$} & Back massage & 3.8000 & \pm .72843 & \multirow[t]{2}{*}{.235} \\
\hline & Reflexology & 3.9600 & \pm .60474 & \\
\hline \multirow{2}{*}{$\begin{array}{l}\text { There is improvement in your } \\
\text { muscles tension and pain level after } \\
\text { intervention }\end{array}$} & Back massage & 4.3200 & \pm .62073 & \multirow[t]{2}{*}{.869} \\
\hline & Reflexology & 4.3400 & \pm .59281 & \\
\hline
\end{tabular}

Level of significance at $p<0.05$

Table (1): Shows that the mean age for the study sample is $(29.75 \pm 5.59)$, the most women are at age 25-30years in back massage, routine care and reflexology group $(50.0 \%, 54.0 \%, 52.0 \%)$ respectively and the most women are house wife $(68.0 \%, 92.0 \%, 80.0 \%)$ respectively.

Figure (1): Represents comparison between groups who receiving back massage, routine care as regard level of education, in back massage group the most women had university education $(38.0 \%)$ followed by women had basic education and read and write in routine care $(32.0 \%)$ and finally women had basic education and university education in reflexology $\operatorname{group}(26.0 \%)$.

Figure (2): Represents comparison between groups who receiving back massage, routine care and reflexology group as regard residence, more than half of women from urban in back massage and reflexology group $(74.0 \%, 66.0 \%)$ and about $(70.0 \%)$ from rural in routine care group. 
Table (2) Shows that there was significant differences on pain reduction after applying back massage on study group compared with before intervention when cervical dilation $3-5 \mathrm{~cm}$ $(.0400 \pm .19795, \mathrm{p}=0.000)$ and at $6-8 \mathrm{~cm}$ dilation $(.4600 \pm .50346 \mathrm{P}=0.000)$ and $9-10 \mathrm{~cm}(.9400 \pm .23990$, $\mathrm{P}=.000)$.

Table (3): Shows that there was significant differences on pain reduction after applying reflexology on study group compared with before intervention when cervical dilation $3-5 \mathrm{~cm}$ $(.0000 \pm .0000, \mathrm{p}=0.000)$ and at $6-8 \mathrm{~cm}$ dilation $(.1600 \pm .37033, \mathrm{P}=0.000)$ and $9-10 \mathrm{~cm}(.9600 \pm .19795$, $\mathrm{P}=.000)$.

Table (4): Shows that there are highly statistically significant differences regarding satisfaction items between applying routine care of the hospital and back massage at the first stage of labor.

Table (5): Shows that there are no statistically significant differences regarding satisfaction items between applying back massage and reflexology at the first stage of labor in all items except in the item number 1 and item number 2 there are statistically significant differences between two groups with $(\mathrm{p}=$ $.001, \mathrm{p}=.004)$ respectively.

\section{Discussion}

When a woman faces the childbirth process for the first time, she often feels anxiety because coping with labor pain is usually viewed as an anxious moment. Labor pain is considered the most unpleasant aspect of labor experience. Labor pain is progressive, with rapid alterations of its location and an increase in severity with advancing dilatation and intensity of uterine contractions.( Santana., et al., 2013)

Pain relief can be done by using two methods pharmacological and non-pharmacological methods. Non-pharmacological methods (NPM) are an option to replace analgesia during labor/delivery, and to support the parturient in dealing with her pain complaints. These methods include: breathing techniques, hydrotherapy (bath, water delivery and immersion bath), massage, acupuncture/acupressure, transcutaneous electrical nerve stimulation, reflexology and hypnosis.( Adams., et al., 2015)

The current study is aimed to evaluate effect of nonpharmacological methods on pain reduction in first stage of labor at Sohag University Hospital.

In present study the age of more than half of women were 25-30 years old ,this results were similar to (Gallo., et al., 2013) who performed their study about "Massage reduced severity of pain during labor" their ages ranged from 20-30 years old and it is similar to (Mahmoud, 2014) who performed their study about " Effect of Heat and Cold Therapy during the First Stage of Labor on Women Perception of Birth
Experience: A Randomized Controlled Trial "which concluded that age ranged from 18-35years old.

In present study more than half of women were house wife in back massage group this was close to results of the study reported by (Mansour \& Nomani, 2016) about "The Effect of Aromatherapy Massage Using Lavender Oil on the Level of Pain and Anxiety During Labor Among Primigravida Women" which concluded that about more than half of women were house wife in study group.

The educational level in our study, revealed the following: More than one-third had university education in back massage group and this was almost similar to results reported by (Mansour \& Nomani, 2016) who performed his study about " The Effect of Aromatherapy Massage Using Lavender Oil on the Level of Pain and Anxiety During Labor Among Primigravida Women" which concluded that about more than one-third had university education in study group.

In our study as regard residence, more than half of women from urban and less than half of participants from rural area this was similar to results reported by (Mansour \& Nomani, 2016) who performed their study about " The Effect of Aromatherapy Massage Using Lavender Oil on the Level of Pain and Anxiety During Labor Among Primigravida Women" the study was conducted in the labor department at ElShatby Maternity University Hospital in Alexandria, Egypt which concluded that about more than half of women were urban in study group.

In our study as regard labor pain scores at the first stage of labor before and after applying back massage there was statistical difference before and after intervention this was similar to results reported by (Zohreh, et al., 2016) who performed their study about "The impact of manual massage on intensity and duration of pain at first phase of labor in primigravid women" the study was conducted at Amiralmomenin Hospital in Zabol, Iran, which concluded that there were significant differences before and after applying massage in two groups.

In our study as regard labor pain scores at the first stage of labor before and after applying reflexology there was statistical difference before and after intervention this was similar to results reported by (Dolatian, et al., 2011) who performed their study about "The Effect of Reflexology on Pain Intensity and Duration of Labor on Primiparas" which concluded that there were significant differences before and after applying reflexology between reflexology group, routine care group and support group.

More over satisfaction of women in routine care of the hospital and reflexology group there are highly statistically significant differences about the 
intervention, this results were constant with results reported by ( Abdulaziz, et al., 2017) who performed their study about " Effect of foot reflexology on pain and outcomes of labor " which concluded that reflexology was very effective method in reliving labor pain and improving outcomes of labor and increasing women's satisfaction

Our study revealed that back massage and reflexology significantly reduced the intensity of pain and increased the women's satisfaction except in two items this was matched with results reported by (Gallo, et al., 2013) who performed their study about "Massage reduced severity of pain during labor" which concluded that massage therapy increased the women's satisfaction.

\section{Conclusion}

Based on the finding of the present study, It concluded that there is a valid evidence for effect of using non- pharmacological methods which included back massage and reflexology on pain reduction in women who are in first stage of labor.

\section{Recommendation}

Based on the findings of the current study, the following recommendations are suggested

- Educate and train all nurses in obstetrics emergency department about nonpharmacological methods in relieving labor pain to be able to provide the knowledge and application correctly and completely including how to deal with pain associated with labor in every stage.

- Further studies of efficacy as well as effectiveness are needed to determine the clinical applicability of back massage and reflexology in other type of pain and done in a large sample and compare them with other alternative therapy.

\section{References}

1. Abdel Fadeel A., (2015): Effect of Ice Cold Massage and Acupressure on Labor Pain and Labor Duration: A Randomized Controlled Trial. Journal of Natural Sciences Research. Vol.5, No.22

2. Abdel Ghani M., (2014): Effect of Heat and Cold Therapy during the First Stage of Labor on Women Perception of Birth Experience: A Randomized Controlled Trial; Vol.4, No.26.

3. Abdulaziz S., El-Refaye E., Abd El Hameed A., Ibrahem M., (2017): Effect of foot reflexology on pain and outcomes of labor. The 18th International Scientific Conference 16-17.
4. Adams J., Frawley J., Steel A., Broom A., Sibbritt D., (2015): Use of pharmacological and non-pharmacological labour pain management techniques and their relationship to maternal and infant birth outcomes: examination of a nationally representative sample of 1835 pregnant women. Midwifery.;31(4):458-63

5. Adel F., Ahmed M., (2017): Effect of Back Massage and Relaxation Training on The Act of Labor: A Randomized Controlled Clinical Trial. International Journal of ChemTech Research.; Vol.10 No.2, pp 243-252.

6. Bahri Binabaj N., Latif Nejad R., Esmaili H., (2008): Study of mother's continues support during labor phases on decreasing behavioral reactions and physiologic responses duo to labor pain. Quarterly Journal of Sabzevar University of Medical Sciences; 11(1): 24-33.

7. Davim R., Vasconcelos Torres G., Melo E., (d2010): Non- pharmacological strategies on pain relief during labor: pre-testing of an instrument. Revista Latino-Americana de Enfermagem.;15(6)

8. Dolatian M., Hasanpour A, Montazeri S., Heshmat R, Alavi H., (2011): The Effect of Reflexology on Pain Intensity and Duration of Labor on Primiparas. Iran Red Crescent Med J; 13(7): 475-479.

9. Funai E., Norwitz E., (2012): Management of normal labor and delivery [Online]. Available from: URL: http://www.uptodate.com.

10. Gallo, R., Santana, L., Ferreira, C., Marcolin, A., PoliNeto, O., Duarte, G., \& Quintana, S., (2013). Massage reduced severity of pain during labor: A randomised trial. Journal of physiotherapy, 59(2), pp.109116.

11. Gousia B., (2015): A study to assess the effectiveness of back massage during first stage of labor among expectant mother's in selected maternity hospital, in Gulbarga. Unpublished thesis of Rajiv Gandhi University of Health Sciences.

12. Kamali Fard M., Allahverdi Zade S., (2010): Nonpharmacological methods for relieving labor pain. 1st ed. Tehran: Ghahazi Jahani Publication. p. 53. (Persian).

13. Mansour L., Nomani I.. (2016): The Effect of Aromatherapy Massage Using Lavender Oil on the Level of Pain and Anxiety During Labor Among Primigravida Women. American Journal of Nursing Science. Vol. 5, No. 2, pp. 37-44. selected maternity hospital, in Gulbarga.. Available at 
http://www.cancer.gov/cancertopics/factsheet/ Therapy

14. Matourypour, P., Vanaki, Z., Zare, Z., Mehrzad, V., Dehghan M,Ranjbaran M. (2016): Investigating the effect of therapeutic touch on the intensity of acute chemotherapy-induced vomiting in breast cancer women under chemotherapy. Iran J Nurs Midwifery Res ;21:255.

15. National Cancer Institute, (2014): Fact sheet: targeted cancer therapies of pain at first phase of labor in primigravid women. International Journal of Medicine Research; Volume 1; Issue 4; Page No. 16-18

16. Potter, P., Perry, A., (2009): Fundamentals of nursing. $7^{\text {th }}$ ed. Philadelphia: Elsevier Mosby; p. 1070 .

17. Smith, C., Levett, K., Collins, C., Jones, L., (2018): Massage, reflexology and other manual methods for pain management in labor (review) The Cochrane Collaboration.

18. Sullivan, N., (2005): Pain Relife in labor. Oregon Health science university school of nursing [Online]. Available from:http://www.midwifeinfo.com/topicpainrelief.Php/

19. Wall P., Melzack R., Bonica J., (2000): Textbook of pain. New York: Churchill Livingstone; p. 490.

20. Zohreh S., Forghani F., Heidari M., Masinaei N., Shahdadi H., (2016): The impact of manual massage on intensity and duration of pain at first phase of labor in primigravid women.Volume 1; Issue 4; Page No. 16-18. 